\title{
High-efficiency asymmetrical half-bridge converter without electrolytic capacitor for low-output-voltage ac-dc LED drivers
}

\author{
Manuel Arias ${ }^{1}$, Marcos Fernández ${ }^{1}$, Diego G. Lamar ${ }^{1}$, Didier Balocco ${ }^{2}$, Almadidi Diallo², Javier Sebastián ${ }^{1}$ \\ ${ }^{1}$ Universidad de Oviedo, Electronic Power Supply Systems group \\ Edificio 3, Campus de Viesques s/n, 33204 Gijón, SPAIN, \\ ${ }^{2}$ AEG Power Solutions \\ 4 Rue Louis de Broglie, 22300 Lannion, FRANCE
}

\begin{abstract}
Due to their high reliability and luminous efficacy, HB-LEDs are being widely used in lighting applications and, therefore, their power supplies are required to have also high reliability and efficiency. A very common approach for achieving this in ac-dc applications is using a two-stage topology. The Power Factor Corrector Boost converter operating in Boundary Conduction Mode is a very common converter used as first stage. It is normally designed without electrolytic capacitors, improving reliability but also increasing the low-frequency ripple of the output voltage. The Asymmetrical Half-Bridge (AHB) is a perfect option for the second stage as it has very high efficiency, it operates at constant switching frequency and its output filter is small (i.e., it can be also easily implemented without electrolytic capacitors). Moreover, the AHB is an excellent candidate for Self-Driven Synchronous Rectification (SD-SR) as its transformer does not have dead times. However, the standard configuration of the SD-SR must be modified in this case in order to deal with the transformer voltage variations due to the input voltage ripple and, more important, due to the LED dimming state. This modification is presented in this paper. Another important issue regarding the AHB is that its closed loop controller cannot be very fast and it cannot easily cancel the previously-mentioned low-frequency ripple. In this paper, a feed-forward technique, specifically designed to overcome this problem, is also presented.
\end{abstract}

The experimental results obtained with a $60-\mathrm{W}$ topology show that efficiency of the AHB may be very high $(\mathbf{9 4 . 5 \% )}$ while the inherent control problems related to the AHB can be overcome by the proposed feed-forward technique.

Keywords: LED drivers, ac-dc converter, dc-dc converter, Asymmetrical Half Bridge, self-driven synchronous rectification, low-output voltage.

\section{INTRODUCTION}

High-Brightness Light Emitting Diodes (HB-LEDs) are considered the future trend in lighting applications for several reasons $[1,2]$. On the one hand, their theoretical luminous efficacy is the highest one. In fact, nowadays their efficacy $(150 \mathrm{~lm} / \mathrm{W})$ is only exceeded by lowpressure sodium technology (around $190 \mathrm{~lm} / \mathrm{W}$ ). On the other hand, their reliability is very high, reaching more than 50,000 hours of lifetime. Besides, there are many other reasons that make HB-LEDs standing out in comparison to the other lighting devices: they are environmentally friendly, they are resistant to shock and vibrations as they are solid-state devices, they have a wide chromatic variety, etc.
The main issue regarding their power supplies is that they should have the same advantages as HB-LEDs have: high efficiency and high reliability. Other important feature frequently demanded to these power supplies is galvanic isolation [3] (sometimes due to regulations and sometimes due to customer requirements). Besides, Power Factor Correction is mandatory in all ac-dc converters in order to comply with IEC61000-3-2 Regulation (in class C if the input power is higher than $25 \mathrm{~W}$ and in class $\mathrm{D}$ if the input power is smaller than $25 \mathrm{~W}$ ). Therefore, many highefficiency high-reliability topologies for LED-lighting applications have been presented recently in the literature [4]. All the existing topologies can be classified attending to their number of stages: one, two or three.

While one-stage and integrated two-stage topologies [5-7] are the preferred option when cost is of primary concern, two [8-10] and three-stage [11] topologies are chosen when efficiency and reliability are the main design targets. For example, street lighting is an application in which the cost of the LED driver is less significant than its efficiency due to the amount of energy consumed by street lighting every day. Besides, the cost of maintaining and replacing this kind of drivers is very high and, therefore, reliability is a key point [12]. Hence, street lighting is an application in which two or three-stage topologies are the preferred option. On the other hand, one-stage topologies are usually chosen for home and commercial applications, such as LED-based replacement lamps [13].

A two-stage topology based on the Boost converter as first stage and the AHB as second stage has already been presented in [14]. The Boost converter, working as Power Factor Corrector (PFC), may reach efficiency as high as 97-98\%. Besides, it may be built without electrolytic capacitor, boosting its reliability and reaching a lifetime similar to the one that HB-LEDs have. The AHB [15-19] is in charge of providing the galvanic isolation and regulating the output voltage, if several LED strings are supplied by the same converter [20-22], or the output current, if each LED string has its own second stage (see Fig. 1a and Fig. 1b). As explained in [14], this topology has proven to be a perfect option for lighting applications: its efficiency is very high (reaching 94\%) and the size of the output filter is very small, making possible to implement it without electrolytic capacitors. Therefore, the two main requirements for LED-based lighting applications are fulfilled. Nevertheless, [14] deals with a 


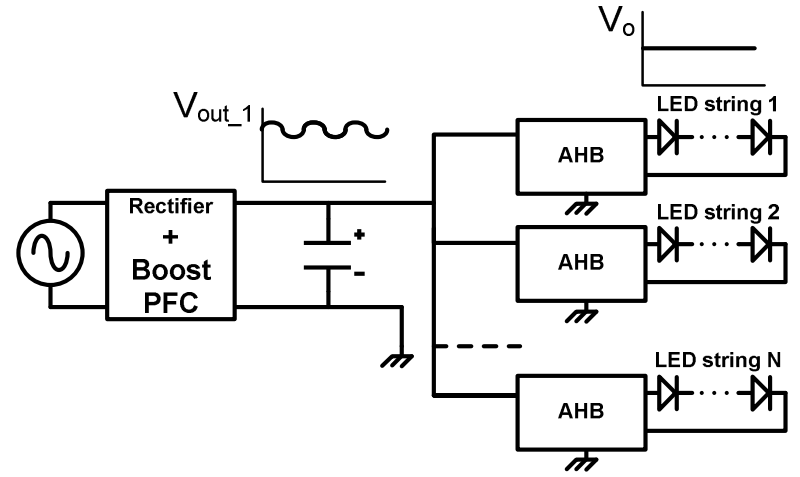

a)

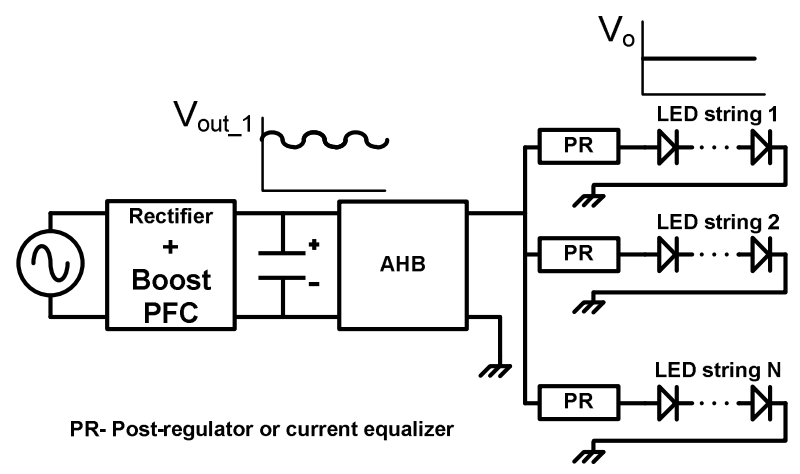

b)

Fig. 1. Proposed two stage topology a) with one second stage per LED string; b) with one second stage common to all LED strings (equalizers or post-regulators are then required).

high-voltage $(140 \mathrm{~V})$, low-current $(0.350 \mathrm{~A})$ street lighting application where Synchronous Rectification (SR) is not needed. In this paper, the AHB is designed for a completely-different low-voltage $(12 \mathrm{~V})$, high-current (5 A) application and, as a consequence, Synchronous Rectification (SR) is mandatory for reaching high efficiency. It should be noted that the AHB is a perfect candidate for Self-Driven (SD) SR technique [19]. Nevertheless, the SD-SR technique must be adapted in order to deal with the fact that the transformer voltage varies with the input voltage ripple and with the LED dimming state.

Another important task of the AHB in this application is counteracting the low-frequency ripple that affects the output voltage of the PFC due to the absence of an electrolytic capacitor at the output of this stage (see Fig. 1) [23-26]. This attenuation is mandatory because if the ripple reaches the output of the second stage (i.e., the AHB), the emitted light will be affected by flickering [27, 28]. Moreover, the amount of light emitted by LED strings is nearly proportional to the amount of current driven by them [1]. Considering the low value of the dynamic resistance of this kind of devices, the relative value of the low-frequency ripple affecting the voltage applied to the LED string will turn into a considerably higher relative value of the current ripple. Therefore, even the lowest ripple in the second stage output voltage may turn into considerable light flickering. Obviously, the second stage cannot use electrolytic capacitors either. Therefore, this ripple attenuation has to be accomplished by means of the closed loop regulation of the AHB. Nevertheless, the AHB has some limitations for obtaining a fast response due to its complex output voltage-control transfer function [15]. This problem becomes worse when the switching frequency is lowered in order to improve the efficiency when SD-SR is used. In this paper, a straightforward feed-forward technique is presented in order to overcome the aforementioned control limitations.

This paper, which is only focused on the AHB (second stage) as the Boost converter (first stage) is an already-well-known topology, is organized as follows. In section II, the main features regarding the AHB are reviewed. In section III, the SD-SR technique is detailed. In section IV, the feed-forward technique specifically designed for this converter is explained. Finally, in section $\mathrm{V}$ all the experimental results are gathered while in section VI the conclusions are presented.

\section{REVIEW OF THE MAIN FEATURES OF THE AHB}

In this section, only the main characteristics of the AHB will be explained in order to provide the necessary background to the following sections. A deep explanation regarding the optimized design of the transformer and the achievement of the Zero-Voltage Switching (ZVS) is not going to be given here as it can be found in [14].

The schematic of the AHB can be seen in Fig. 2. Its main feature is that primary switches are driven with complementary signals and, consequently, one of them is always turned on. As the volt-second balance in the magnetizing inductance has to be maintained, these complementary driving signals imply that the voltages of the input capacitors are not necessarily equal:

$$
\begin{gathered}
\mathrm{V}_{\mathrm{C} 1}=(1-\mathrm{D}) \cdot \mathrm{V}_{\mathrm{g}}, \\
\mathrm{V}_{\mathrm{C} 2}=\mathrm{D} \cdot \mathrm{V}_{\mathrm{g}},
\end{gathered}
$$

where $\mathrm{V}_{\mathrm{C} 1}$ and $\mathrm{V}_{\mathrm{C} 2}$ are the voltages across the input capacitors $C_{1}$ and $C_{2}, D$ is the duty cycle of $M_{1}$ and $V_{g}$ is the input voltage.

The volt-second balance in the output inductor leads to the following equation:

$$
\mathrm{V}_{\mathrm{o}}=\mathrm{n}_{1} \cdot \mathrm{V}_{\mathrm{C} 1} \cdot \mathrm{D}+\mathrm{n}_{2} \cdot \mathrm{V}_{\mathrm{C} 2} \cdot(1-\mathrm{D})
$$

where $\mathrm{V}_{\mathrm{o}}$ is the output voltage of the AHB and $\mathrm{n}_{1}$ and $\mathrm{n}_{2}$ are the turns ratios of the transformer.

Substituting (1) and (2) into (3), we obtain:

$$
\mathrm{V}_{\mathrm{o}}=\mathrm{V}_{\mathrm{g}} \cdot \mathrm{D} \cdot(1-\mathrm{D}) \cdot\left(\mathrm{n}_{1}+\mathrm{n}_{2}\right)
$$

As it can be seen, the output voltage is not linear dependent on the duty cycle. This is a key point in the feed-forward design that will be presented in section IV. 


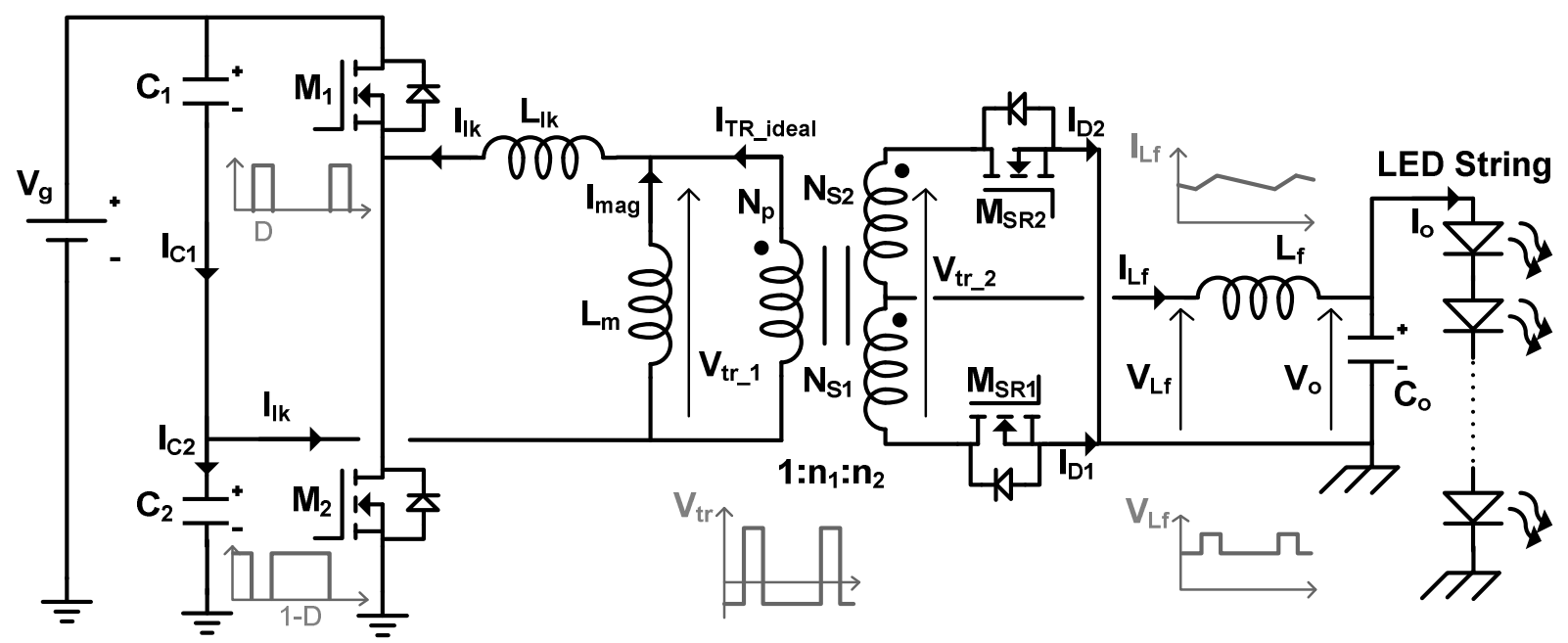

Fig. 2. Schematic of the proposed AHB.

For the SD-SR presented in section III, it is important to notice that the voltage across the secondary side of the transformer (considering both secondary windings) is:

$$
\mathrm{V}_{\mathrm{tr}_{-} 2}=\mathrm{V}_{\mathrm{tr}_{-} 1} \cdot\left(\mathrm{n}_{1}+\mathrm{n}_{2}\right)
$$

so $\mathrm{V}_{\mathrm{tr} \_2}$ only presents two possible values depending on the state of the primary switches:

$$
\mathrm{V}_{\mathrm{tr}_{-} 2}=+(1-\mathrm{D}) \cdot \mathrm{V}_{\mathrm{g}} \cdot\left(\mathrm{n}_{1}+\mathrm{n}_{2}\right)
$$

when $\mathrm{M}_{1}$ is turned on, and

$$
\mathrm{V}_{\mathrm{tr}_{-} 2}=-\mathrm{D} \cdot \mathrm{V}_{\mathrm{g}} \cdot\left(\mathrm{n}_{1}+\mathrm{n}_{2}\right)
$$

when $\mathrm{M}_{2}$ is turned on. As it can be seen, even when the input voltage is constant, the voltage of the secondary side of the transformer may vary due to the duty cycle variations that take place due to dimming. Therefore, the standard SD-SR technique is not valid and it has to be wisely modified in order to obtain suitable driving signal for the SR MOSFETs.

\section{SELF-DRIVEN SYNCHRONOUS RECTIFICATION}

For low-voltage high-current application (such as the one explained in this paper), SR is mandatory in order to achieve high efficiency. Among all the possibilities, SD$\mathrm{SR}$ is the simplest one as the driving signals of the SR MOSFETs are obtained from the secondary winding of the transformer. Therefore, no additional controllers are necessary and no problems with programmed delays will appear. Nevertheless, the SD-SR is a more desirable approach when the peak value of the voltage across the secondary winding does not change when the output voltage is modified. If the voltage across the secondary winding does not change with the output voltage variations, the driving circuit can be easily designed in order to assure that the driving signals of the SR MOSFETs are inside the acceptable voltage limits. In the AHB, the voltage in the secondary side of the transformer depends not only on the input voltage but also on the duty cycle (see (6) and (7)). Therefore, the voltage applied to the gate of the SR MOSFETs is variable and, for certain duty cycles, it may reach unacceptable voltage levels. In Fig. 3, the voltages applied to the gates of the SR MOSFETs are shown for the whole input voltage range Also, this figure shows the maximum $\mathrm{V}_{\mathrm{GS}}$ (exceeding this voltage would mean the breakdown of the MOSFET) and the minimum one (any $\mathrm{V}_{\mathrm{GS}}$ lower than this limit will not properly bias the MOSFET). As can be seen in Fig. 3, there are certain values of $\mathrm{V}_{\mathrm{g}}$ that implies the breakdown of one or both devices (in fact, $\mathrm{M}_{\mathrm{SR}_{-} 1}$ would break for any possible value of $\mathrm{V}_{\mathrm{g}}$ ).

A possible solution is using a zener diode in order to clamp the voltage applied to the gate of the SR MOSFETs and a capacitor that will withstand the exceeding voltage (see Fig. 4a). The main problem is that this capacitor is constantly charging and discharging and that implies switching losses in the converter. Besides, its capacitance has to be larger than the gate capacitance of the SR MOSFET for a proper operation, increasing switching losses even more. Nevertheless, it is possible to solve this problem with a straightforward approach that adapts the voltage of the driving signals to an acceptable value while reducing the switching losses.

As can be seen in Fig. 4b, instead of using the zener diode for clamping the voltage across the SR MOSFET

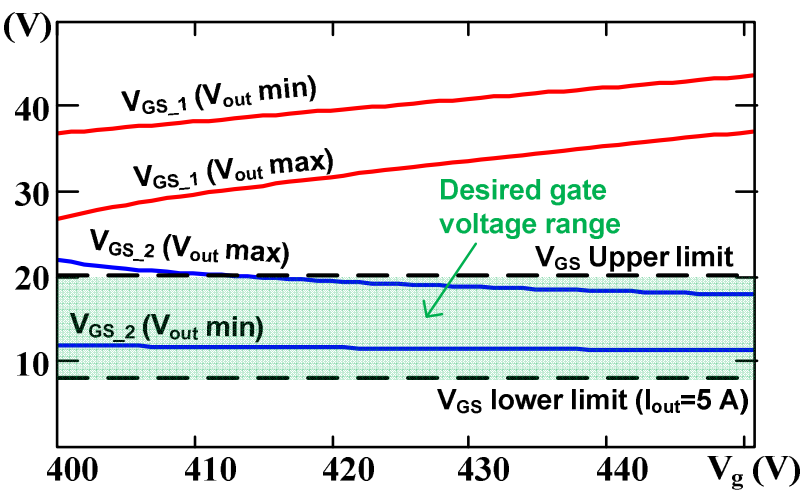

Fig. 3. $\mathrm{V}_{\mathrm{GS}}$ of $\mathrm{M}_{\mathrm{SR}_{1} 1}$ and $\mathrm{M}_{\mathrm{SR} \_2}$ for the maximum and minimum output voltage and for the whole input voltage range. 


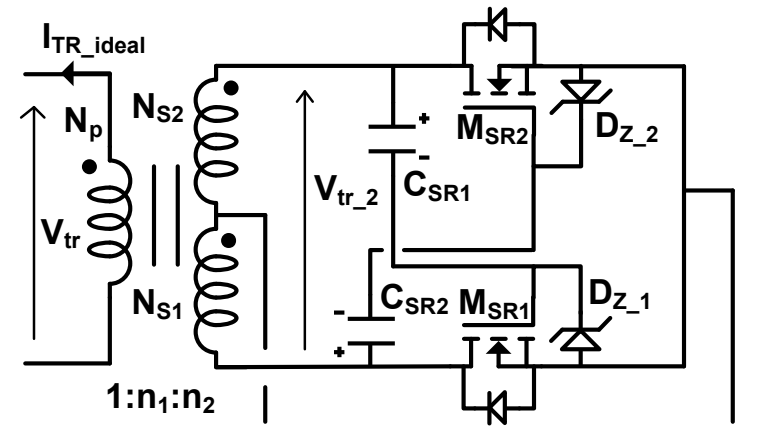

a)

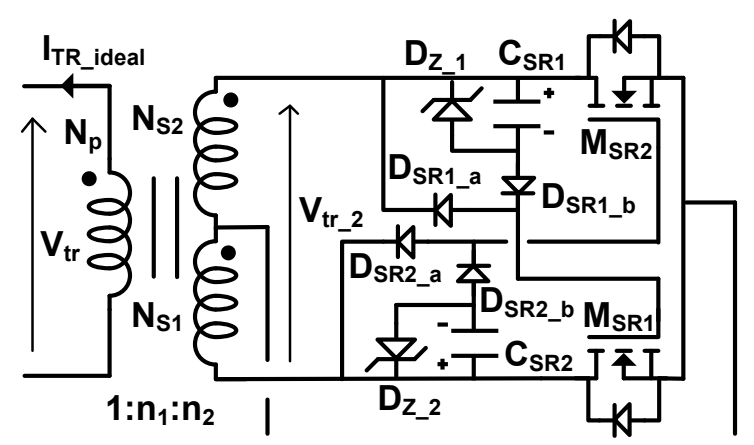

b)

Fig. 4. a) High-switching losses SD-SR circuit; b) Proposed SDSR circuit.

gate, the zener diodes $\mathrm{D}_{\mathrm{Z}_{-} 1}$ and $\mathrm{D}_{\mathrm{Z}_{-} 2}$ are used for clamping the voltage across the capacitors $\mathrm{C}_{\mathrm{SR}_{\_} 1}$ and $\mathrm{C}_{\mathrm{SR}_{2} 2 \text {. Although }}$ this scheme is less effective than clamping the gate voltage directly, it allows us to use diodes $\mathrm{D}_{\mathrm{SR} 1 \_\mathrm{a}}$ and $\mathrm{D}_{\mathrm{SR} 1 \_\mathrm{b}}$ in order to define one circuit for charging the gate capacitance (Fig. 5a) of $\mathrm{M}_{\mathrm{SR} 1}$ and a different one for discharging it (Fig. 5b). Diodes $\mathrm{D}_{\mathrm{SR} 2 \_\mathrm{a}}$ and $\mathrm{D}_{\mathrm{SR} 2 \_ \text {b }}$ develop the same function for $\mathrm{M}_{\mathrm{SR} 2}$. When $\mathrm{V}_{\mathrm{tr} 2}$ is positive and $\mathrm{M}_{\mathrm{SR} 1}$ has to be turned on, diode $\mathrm{D}_{\mathrm{SR} 1 \_b}$ is directly biased and capacitor $\mathrm{C}_{\mathrm{SR} 1}$ is charged to a voltage equal to the zener voltage $\mathrm{V}_{\mathrm{Z}_{-} 1}$ while the voltage applied to the gate of $\mathrm{M}_{\mathrm{SR} 1}, \mathrm{~V}_{\mathrm{GS} \_1}$, is defined by the following equation:

$$
\mathrm{V}_{\mathrm{GS}_{-} 1}=(1-\mathrm{D}) \cdot \mathrm{V}_{\mathrm{g}} \cdot\left(\mathrm{n}_{1}+\mathrm{n}_{2}\right)-\mathrm{V}_{\mathrm{Z}_{-} 1}
$$

When the voltage $V_{\text {tr_2 }}$ is negative and $M_{\mathrm{SR} 2}$ is turned on, diode $D_{S R 1 b}$ is reverse biased, leaving the capacitor $\mathrm{C}_{\mathrm{SR} 1}$ charged with a voltage level equal to $\mathrm{V}_{\mathrm{Z}_{-} 1}$. Besides, the gate of $\mathrm{M}_{\mathrm{SR} 1}$ is discharged through MOSFET $\mathrm{M}_{\mathrm{SR} 2}$, which is turned on, and diode $\mathrm{D}_{\mathrm{SR} 1 \_\mathrm{a}}$. The same explanation is valid for the SD-SR circuitry of $\mathrm{M}_{\mathrm{SR} 2}$. Therefore, the equation that defines the voltage across the gate of $\mathrm{M}_{\mathrm{SR} 2}, \mathrm{~V}_{\mathrm{GS}_{-} 2}$, is:

$$
\mathrm{V}_{\mathrm{GS} \_2}=\mathrm{D} \cdot \mathrm{V}_{\mathrm{g}} \cdot\left(\mathrm{n}_{1}+\mathrm{n}_{2}\right)-\mathrm{V}_{\mathrm{z}_{-} 2}
$$

As can be seen, switching losses are reduced as the capacitors $\mathrm{C}_{\mathrm{SR} 1}$ and $\mathrm{C}_{\mathrm{SR} 2}$ are not constantly charged and discharged.

In Fig. 6, voltages $\mathrm{V}_{\mathrm{GS} \_1}$ and $\mathrm{V}_{\mathrm{GS} \_2}$ are represented for the whole input voltage range when the proposed circuit is used. As it can be seen in this figure, $\mathrm{V}_{\mathrm{GS} 2}$ is inside the acceptable limits for any valid input and output

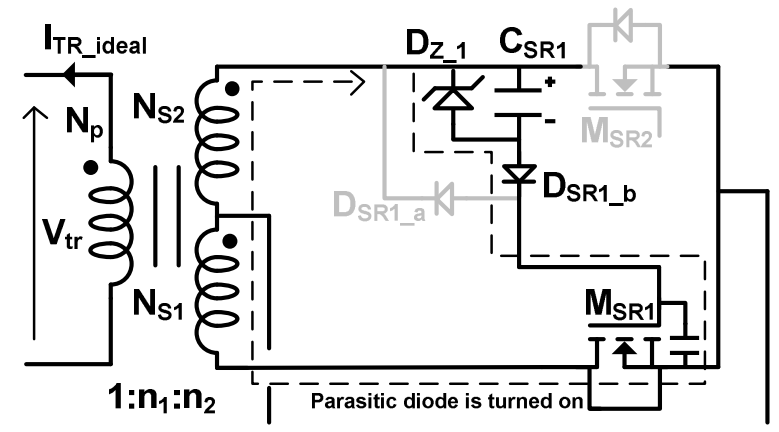

a)

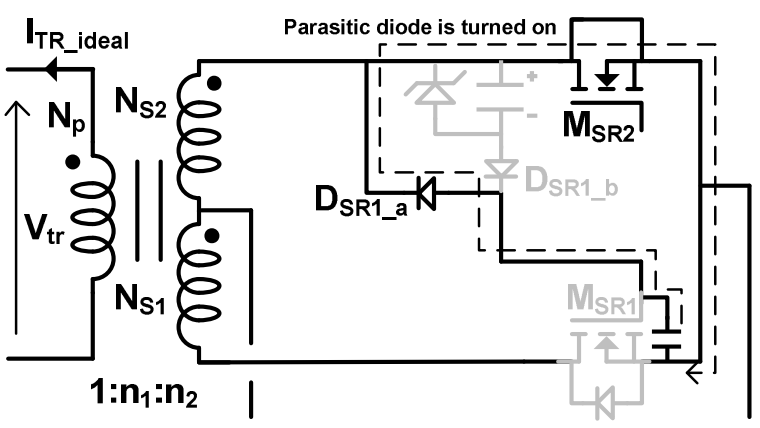

b)

Fig. 5. a) Path of the current when charging the gate capacitance; b) Path of the current when discharging the gate capacitance.

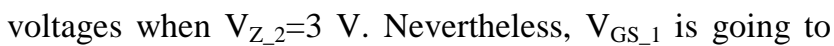
exceed one of the limits. As exceeding the upper limit implies the MOSFET breakdown, the value of $\mathrm{V}_{\mathrm{Z}_{-} 1}$ should assure that this limit is not exceeded. Nevertheless, this means that for certain values of the input voltage, $\mathrm{V}_{\mathrm{GS} \_1}$ is not as high as it should be in order to keep moderate conduction losses in MOSFET $\mathrm{M}_{\mathrm{SR} 1}$. As it has been mentioned, choosing a different zener diode (in this case, with $\mathrm{V}_{\mathrm{Z}_{1} 1}=17.5 \mathrm{~V}$ ) would lead to a situation in which the lower limit is not exceeded by $\mathrm{V}_{\mathrm{GS}_{1}}$ but the upper one actually is. Therefore, the problem of the circuit proposed in Fig. $4 \mathrm{~b}$ is that the slope value of $\mathrm{V}_{\mathrm{GS}_{-} 1}$ in Fig. 6 is too high and it is not possible to select a zener diode that ensures that $\mathrm{V}_{\mathrm{GS}_{-} 1}$ is inside the limits for any input and output voltages combination. It is possible to solve this problem by using the driving circuit presented in Fig. 7a for $\mathrm{M}_{\mathrm{SR} 1}$. It should be noted that the scheme of the driving circuit for $\mathrm{M}_{\mathrm{SR} 2}$ keeps unchanged. It should be also noted that capacitor $C_{W}$ is going to be charged to a voltage $V_{C W}$ equal to the voltage of the secondary winding $\mathrm{N}_{\mathrm{s} 2}$ when $\mathrm{V}_{\mathrm{tr} \_2}$ is positive (i.e., $\mathrm{M}_{\mathrm{SR} 1}$ is turned on):

$$
\mathrm{V}_{\mathrm{CW}}=(1-\mathrm{D}) \cdot \mathrm{V}_{\mathrm{g}} \cdot \mathrm{n}_{2}
$$

Therefore, the voltage $\mathrm{V}_{\mathrm{GS} \_1}$ when $\mathrm{M}_{\mathrm{SR} 1}$ is turned on can be expressed as:

$$
\begin{aligned}
\mathrm{V}_{\mathrm{GS}_{-} 1}= & (1-\mathrm{D}) \cdot \mathrm{V}_{\mathrm{g}} \cdot\left(\mathrm{n}_{1}+\mathrm{n}_{2}\right)-\mathrm{V}_{\mathrm{CW}}-\mathrm{V}_{\mathrm{Z}_{-} 1}, \\
= & (1-\mathrm{D}) \cdot \mathrm{V}_{\mathrm{g}} \cdot \mathrm{n}_{1}-\mathrm{V}_{\mathrm{Z}_{-} 1},
\end{aligned}
$$

As can be seen in Fig. $7 b$, the slope of the equation (11) is lower than in (8) and, therefore, now it is possible to find a value of $\mathrm{V}_{\mathrm{Z}_{1} 1}$ (different from the value proposed 


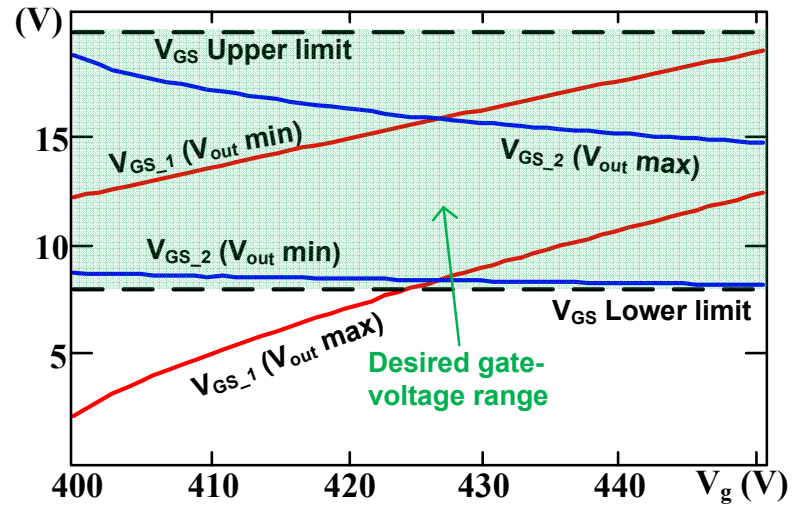

Fig. 6. $\mathrm{V}_{\mathrm{GS}}$ of $\mathrm{M}_{\mathrm{SR} \_1}$ and $\mathrm{M}_{\mathrm{SR} \_2}$ for the maximum and minimum output voltage and for the whole input voltage range.

in Fig. 6) that makes $\mathrm{V}_{\mathrm{GS} \_1}$ to be inside the limits for any input voltage. In other words, $\mathrm{C}_{\mathrm{W}}$ cancels the voltage of one of the secondary windings.

As it can be seen, the two proposed circuits (see Fig. 7a) allow SD-SR to be used in the AHB, maintaining the voltage across the gate of the SR MOSFETs in between the limits needed for their suitable operation. All the figures shown in this section presents the gate voltages for an output voltage of $12 \mathrm{~V}$ and an input voltage ripple of $12 \%$. Nevertheless, the circuits proposed in Fig. 4 and Fig. 7 can be adapted for other conditions of output voltage and input voltage ripple.

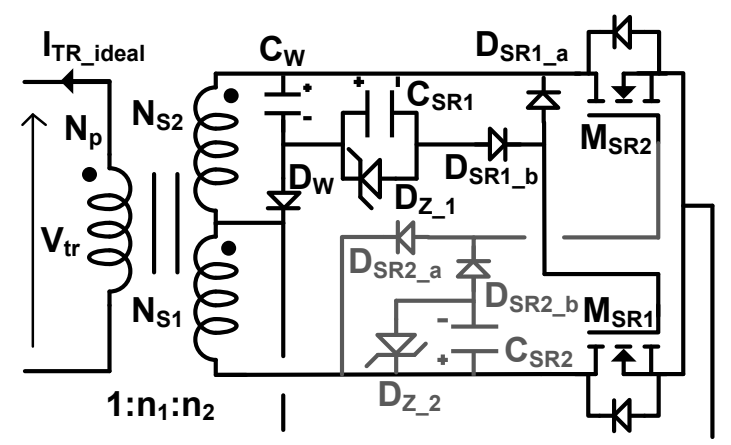

a)

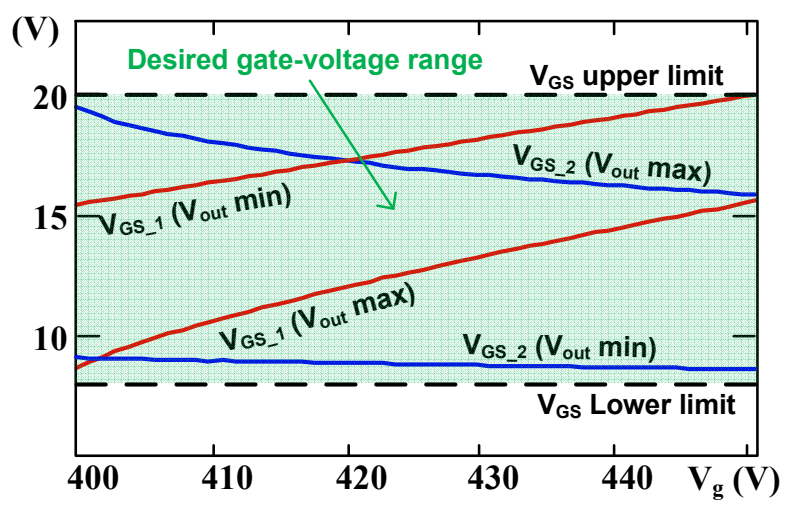

b)

Fig. 7. a) Proposed SD-SR driving circuit and b) resulting gate voltages.

$\left(\mathrm{V}_{\mathrm{Z}_{\_} 1}=11 \mathrm{~V}, \mathrm{~V}_{\mathrm{Z}_{\_} 2}=3 \mathrm{~V}, \mathrm{~V}_{\mathrm{g} \_ \text {nom }}=425 \mathrm{~V}, \mathrm{~V}_{\mathrm{g} \_\max }=450 \mathrm{~V}, \mathrm{~V}_{\mathrm{g} \_ \text {min }}=400\right.$

$\mathrm{V}, \mathrm{n}_{1}=0.084, \mathrm{n}_{2}=0.04, \mathrm{~V}_{\text {out } \max }=12 \mathrm{~V}, \mathrm{~V}_{\text {out } \min }=6 \mathrm{~V}$.).

\section{FEED-FORWARD TECHNIQUE}

As high reliability is achieved by, among other things, not using electrolytic capacitors in the LED driver implementation, the output voltage of the first stage is going to be affected by a low-frequency ripple that cannot be neglected. As it has been said, if this ripple reaches the LED string, it may cause serious flickering problems, aggravated due to the low value of the dynamic resistance of the HB-LEDs. Therefore, it is mandatory for the second stage to cancel this ripple. Nevertheless, it is very well known that the AHB has a complex transfer function between the control parameter (duty cycle) and the controlled parameter (output voltage or current) [15]. This fact makes difficult to design a control feedback loop fast enough to attenuate the input ripple properly. This difficulty increases if the converter is designed at relatively-low switching frequency in order to obtain as high efficiency as possible. It should be noted that the operation at relatively-low frequency does not represent a big penalty for the inductor size due the special waveform presented by the voltage $\mathrm{V}_{\mathrm{Lf}}$ (see Fig. 2).

The small-signal analysis presented in [15] leads to the following equations:

$$
\begin{aligned}
& \mathrm{G}_{\mathrm{vo}_{-} \mathrm{d}}(\mathrm{s})=\left.\frac{\hat{\mathrm{v}}_{\mathrm{o}}}{\hat{\mathrm{d}}}\right|_{\hat{\mathrm{v} g}=0}=\left(\mathrm{N}_{1}+\mathrm{N}_{2}\right) \cdot \mathrm{V}_{\mathrm{g}} \cdot \\
& \frac{\frac{\mathrm{N}_{1}}{\mathrm{~N}_{1}+\mathrm{N}_{2}} \cdot \mathrm{L}_{\mathrm{m}} \cdot \mathrm{C}_{\mathrm{p}} \cdot \mathrm{s}^{2}+\frac{\mathrm{N}_{2}}{\mathrm{~N}_{1}+\mathrm{N}_{2}} \cdot\left(\mathrm{n}_{1}+\mathrm{n}_{2}\right) \cdot \mathrm{M} \cdot \frac{\mathrm{L}_{\mathrm{m}}}{\mathrm{R}_{1}} \cdot \mathrm{s}+1}{\mathrm{~L}_{\mathrm{m}} \cdot \mathrm{C}_{\mathrm{p}} \cdot \mathrm{s}^{2}+\mathrm{N}_{2}^{2} \cdot \frac{\mathrm{L}_{\mathrm{m}}}{\mathrm{Z}(\mathrm{s})} \cdot \mathrm{s}+1} \\
& \frac{1}{\mathrm{~L}_{\mathrm{f}} \cdot \mathrm{C}_{\mathrm{f}} \cdot \mathrm{s}^{2}+\frac{\mathrm{L}_{\mathrm{f}}}{\mathrm{R}_{1}} \cdot \mathrm{s}+1}
\end{aligned}
$$

where,

$$
\begin{gathered}
\mathrm{N}_{1}=\mathrm{n}_{1} \cdot(1-\mathrm{D})-\mathrm{n}_{2} \cdot \mathrm{D}, \\
\mathrm{N}_{2}=\mathrm{n}_{2} \cdot(1-\mathrm{D})-\mathrm{n}_{1} \cdot \mathrm{D}, \\
\mathrm{M}=\left(\mathrm{n}_{1}+\mathrm{n}_{2}\right) \cdot \mathrm{D} \cdot(1-\mathrm{D}), \\
\mathrm{C}_{\mathrm{p}}=\mathrm{C}_{1}+\mathrm{C}_{2}, \\
\mathrm{Z}(\mathrm{s})=\frac{\mathrm{L}_{\mathrm{f}} \cdot \mathrm{C}_{\mathrm{f}} \cdot \mathrm{R}_{1} \cdot \mathrm{s}^{2}+\mathrm{L}_{\mathrm{f}} \cdot \mathrm{s}+\mathrm{R}_{1}}{\mathrm{R}_{1} \cdot \mathrm{C}_{\mathrm{f}} \cdot \mathrm{s}+1} .
\end{gathered}
$$

In this equations, upper-case letters represent constant values, lower-case letters represent variable values and lower-case letters with ${ }^{\wedge}$ represent perturbed values. $\mathrm{L}_{\mathrm{m}}$ is the magnetizing inductance of the transformer, $\mathrm{R}_{\mathrm{l}}$ is the load resistance, $\mathrm{L}_{\mathrm{f}}$ is the inductance of the output filter and $\mathrm{C}_{\mathrm{f}}$ is its capacitance. It should be taken into account that (12) relates the output voltage with the duty cycle (transfer function $\mathrm{G}_{\mathrm{V}_{\mathrm{od}} \mathrm{d}}(\mathrm{s})$ ). The transfer function between the output current and the duty cycle can be easily obtained by dividing $\mathrm{G}_{\mathrm{Vo}_{\mathrm{d}}}(\mathrm{s})$ by the dynamic 
resistance of the load (i.e., total dynamic resistance of the LED strings). As it was mentioned in section I, depending on the number of LED strings connected in parallel to the same AHB, the most suitable variable to be controller may be the voltage (if several string are connected in parallel to the same AHB) or the current (if each string is connected to its own AHB converter).

Equation (12) allows us to detect a resonance (double pole, double zero) between the input capacitors and the magnetizing inductance of the transformer. The double pole is located at a frequency $\mathrm{f}_{\mathrm{dp}}$ equal to:

$$
\mathrm{f}_{\mathrm{dp}}=\frac{1}{2 \cdot \pi \cdot \sqrt{\mathrm{L}_{\mathrm{m}} \cdot \mathrm{C}_{\mathrm{p}}}},
$$

while the double zero is located at a frequency $\mathrm{f}_{\mathrm{dz}}$ equal to:

$$
f_{d z}=\frac{\sqrt{\frac{N_{1}+N_{2}}{N_{1}}}}{2 \cdot \pi \cdot \sqrt{L_{m} \cdot C_{p}}} .
$$

Normal values of $L_{m}$ and $C_{p}$ for this kind of application result in relative low values of $f_{d p}$ and $f_{d z}$ (around some $\mathrm{kHz}$ ). Besides, the double pole is not located at the same frequency as the double zero. Therefore, they do not cancel each other and this makes difficult to implement a feedback loop controller fast enough to cancel the low-frequency ripple of the output voltage (or current). In other words, the crossover frequency which assures the stability of the AHB is not high enough to guarantee that a $100-\mathrm{Hz}$ or $120-\mathrm{Hz}$ ripple is properly attenuated. However, it should be noted that the load variations (i.e., variations in the characteristics of the HB-LEDs, such as dynamic resistance, knee voltage, relation between forward current and emitted light, etc.) are very slow because they are determined by the warming-up of the LEDs. Therefore, the dynamic requirements of the AHB are not due to the load variations but due to the input voltage ripple. Taking this into account, the control strategy is going to be split in two control loops: a feedback loop and a feed-forward loop.

The feedback control is only in charge of regulating the output voltage/current according to the aforementioned thermal process of the LEDs. Therefore, it can be a very slow, simple and stable controller, overcoming the inherent problem of the regulation of the AHB. On the other hand, the feed-forward loop is going to be specifically designed and optimized for attenuating the effect of the input-voltage, low-frequency ripple without affecting the converter stability. Obviously, there are situations that need to be solved in a very short period of time (open-circuit failure, short-circuit failure, etc.). Actually, those situations are normally cleared by standard protection circuits.

The proposed solution is shown in Fig. 8. For designing the feed-forward compensator, it should be taken into account that it consists of three different and very simple stages. The first one, $\mathrm{K}$, is a voltage divider for sensing the input voltage of the AHB. The second stage, $\mathrm{G}_{\mathrm{lfr} \_ \text {svg }}(\mathrm{s})$, is a first-order band-pass filter designed for twice the line frequency. The third stage, $F F(s)$, is the transfer function of a compensator that has to be wisely designed in order to attenuate the effect of the lowfrequency ripple. For doing so, the transfer function $\mathrm{G}_{\mathrm{vo} \_ \text {vg_ff }}(\mathrm{s})$ that relates the input and the output voltage of the AHB when the feed-forward loop is implemented can be obtained from Fig. 8:

$$
\begin{aligned}
& \left.\frac{\hat{\mathrm{v}}_{\mathrm{o}}}{\hat{\mathrm{v}}_{\mathrm{g}}}\right|_{\hat{\mathrm{V}}_{\text {ref }=0}}=\mathrm{G}_{\mathrm{vo}_{\text {_vg_ff }}}(\mathrm{s})= \\
& =\frac{G_{v_{-} \_v g}(s)+\frac{1}{V_{m}} \cdot K \cdot G_{v_{-} d}(s) \cdot G_{1 f r_{-} s v g}(s) \cdot F F(s)}{1+\frac{G_{v_{0} d}(s) \cdot P I(s)}{V_{m}}},
\end{aligned}
$$

where $\mathrm{PI}(\mathrm{s})$ is the transfer function of the feedback compensator, $\mathrm{V}_{\mathrm{m}}$ is the peak-to-peak value of the sawtooth waveform shown in Fig. 8 and $\mathrm{G}_{\mathrm{vo} \_\mathrm{vg}}(\mathrm{s})$ is [15]:

$$
\begin{aligned}
& \mathrm{G}_{\mathrm{vo} \_\mathrm{vg}}(\mathrm{s})=\mathrm{M} \cdot \frac{\frac{\mathrm{L}_{\mathrm{m}} \cdot \mathrm{C}_{\mathrm{m}}}{\mathrm{M}} \cdot \mathrm{s}^{2}+1}{\mathrm{~L}_{\mathrm{m}} \cdot \mathrm{C}_{\mathrm{p}} \cdot \mathrm{s}^{2}+\mathrm{N}_{2}^{2} \cdot \frac{\mathrm{L}_{\mathrm{m}}}{\mathrm{Z}(\mathrm{S})} \cdot \mathrm{s}+1} . \\
& \frac{1}{\mathrm{~L}_{\mathrm{f}} \cdot \mathrm{C}_{\mathrm{f}} \cdot \mathrm{s}^{2}+\frac{\mathrm{L}_{\mathrm{f}}}{\mathrm{R}_{1}} \cdot \mathrm{s}+1} \\
& \mathrm{C}_{\mathrm{m}}=\mathrm{n}_{2} \cdot(1-\mathrm{D}) \cdot \mathrm{C}_{1}+\mathrm{n}_{1} \cdot \mathrm{D} \cdot \mathrm{C}_{2} .
\end{aligned}
$$

Although equation (20) may seem complex, it should be observed that this equation is valid for any frequency. As has been explained, the crossover frequency of the feedback loop $\mathrm{f}_{\mathrm{fb}}$ is considerably lower than 100-120 $\mathrm{Hz}$ in order to assure stability. Hence, in this analysis $\mathrm{G}_{\mathrm{Vo}_{\mathrm{d}} \mathrm{d}}(\mathrm{s}) \cdot \mathrm{PI}(\mathrm{s}) / \mathrm{V}_{\mathrm{m}}$ can be disregarded due to the low value of $\mathrm{PI}(\mathrm{s})$ at those frequencies (frequencies higher than $\mathrm{f}_{\mathrm{fb}}$ ) and, as a consequence, the transfer function (20) becomes:

$$
\begin{aligned}
& \left.\mathrm{G}_{\mathrm{vo}_{-} \mathrm{vg}_{-} \mathrm{ff}}(\mathrm{s})\right|_{\mathrm{f}>\mathrm{ffb}}= \\
& =\mathrm{G}_{\mathrm{vo} \_\mathrm{vg}}(\mathrm{s})+\frac{1}{\mathrm{~V}_{\mathrm{m}}} \cdot \mathrm{K} \cdot \mathrm{G}_{\mathrm{vo} \_\mathrm{d}}(\mathrm{s}) \cdot \mathrm{G}_{\mathrm{lfr} \_\mathrm{svg}}(\mathrm{s}) \cdot \mathrm{FF}(\mathrm{s}) \cdot
\end{aligned}
$$

The maximum ripple rejection takes place when (23) is equal to zero and that happens when the transfer function of the feed-forward compensator satisfies:

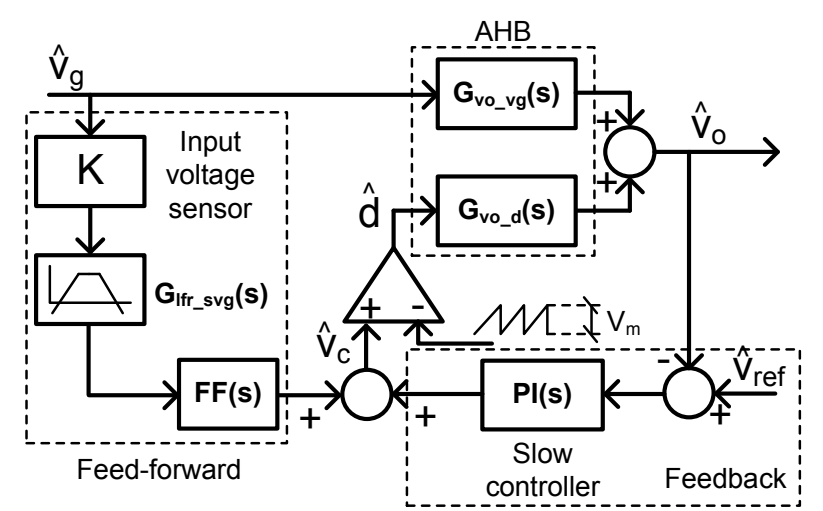

Fig. 8. Block diagram of an AHB with a feed-forward loop. 


$$
F F(s)=-\frac{G_{v_{0} v_{g}}(s) \cdot V_{m}}{K \cdot G_{v_{-} d}(s) \cdot G_{\text {lfr_svg }}(s)} .
$$

The optimum compensator can be easily calculated considering the value of $\mathrm{G}_{\mathrm{Vo} \_\mathrm{Vg}}(\mathrm{s}), \mathrm{G}_{\mathrm{Vo}_{\mathrm{d}} \mathrm{d}}(\mathrm{s})$, and $\mathrm{G}_{\mathrm{lf} \_\mathrm{SVg}}(\mathrm{s})$ in equation (24) at twice the line frequency $2 \omega_{\mathrm{L}}$ (i.e., low frequencies):

$$
\mathrm{FF}\left(2 \omega_{\mathrm{L}} \cdot \mathrm{j}\right)=\mathrm{FF}_{\mathrm{P}}=-\frac{\mathrm{M} \cdot \mathrm{V}_{\mathrm{m}}}{\mathrm{K} \cdot\left(\mathrm{N}_{1}+\mathrm{N}_{2}\right) \cdot \mathrm{V}_{\mathrm{g}}}
$$

From (13), (14) and (15), (25) becomes:/

$$
\mathrm{FF}_{\mathrm{P}}=-\frac{\mathrm{D} \cdot(1-\mathrm{D}) \cdot \mathrm{V}_{\mathrm{m}}}{(1-2 \cdot \mathrm{D}) \cdot \mathrm{V}_{\mathrm{g}} \cdot \mathrm{K}}
$$

Considering that equation (4) allows us to obtain the value of $\mathrm{D}$ as a function of $\mathrm{V}_{\mathrm{o}}$ and $\mathrm{V}_{\mathrm{g}}$, the previous equation can be expressed as:

$$
\mathrm{FF}_{\mathrm{P}}=\frac{\mathrm{V}_{\mathrm{m}} \cdot \mathrm{V}_{\mathrm{o}}}{\mathrm{V}_{\mathrm{g}}^{2} \cdot \mathrm{K} \cdot\left(\mathrm{n}_{1}+\mathrm{n}_{2}\right)} \cdot \frac{1}{\sqrt{1-4 \cdot \frac{\mathrm{V}_{\mathrm{o}}}{\mathrm{V}_{\mathrm{g}} \cdot\left(\mathrm{n}_{1}+\mathrm{n}_{2}\right)}}} .
$$

Fig. 9a shows the audiosusceptibility with feedforward $\left(\mathrm{G}_{\mathrm{vo} \_ \text {vg_ff }}(\mathrm{s})\right)$ and without feed-forward for a practical example. As can be seen in this figure, the audiosusceptibility of the AHB improves if the feedforward loop is included and $\mathrm{FF}(\mathrm{s})$ is properly designed

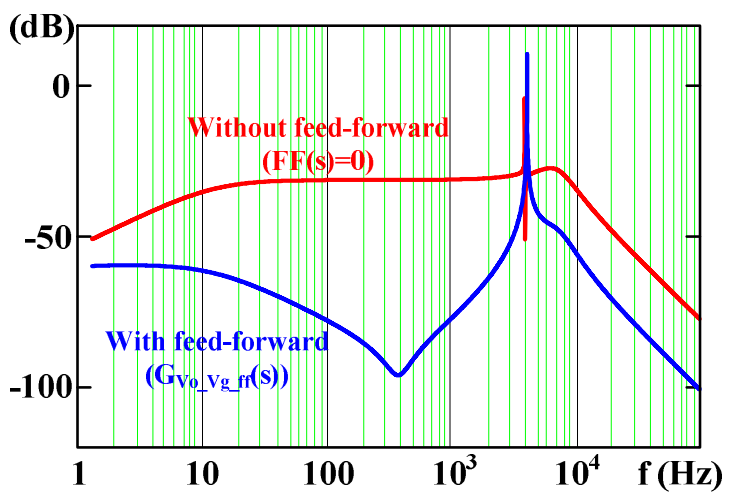

a)

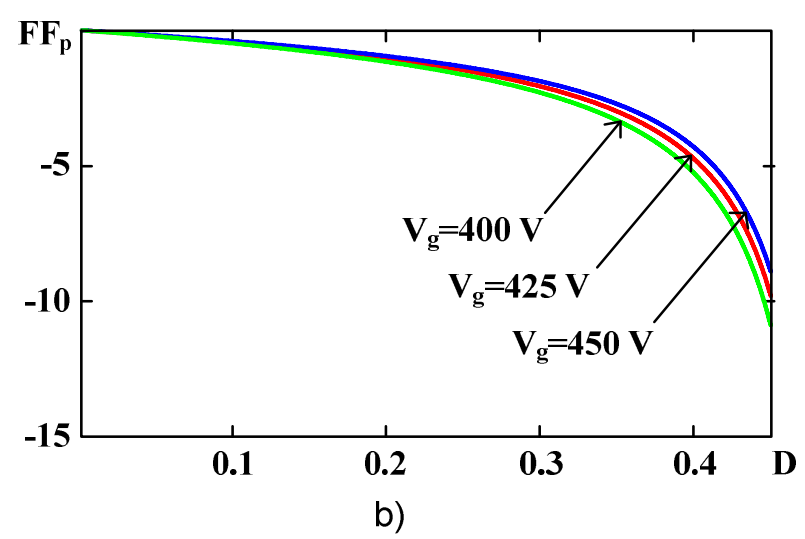

Fig. 9. a) Theoretical audiosusceptibility of the proposed feedforward technique $\left(\mathrm{V}_{\mathrm{g} \_ \text {nom }}=425 \mathrm{~V}, \mathrm{n}_{1}=0.084, \mathrm{n}_{2}=0.04, \mathrm{~V}_{\text {out }}=12 \mathrm{~V}\right.$, $\left.\mathrm{I}_{\text {out }}=5 \mathrm{~A}, \mathrm{~K}=0.0033\right) ; \mathrm{b}$ ) $\mathrm{FF}_{\mathrm{p}}$ for different input voltages and duty cycles. (i.e., according to equation (26)). In this example, the audiosusceptibility decreases from $-37 \mathrm{~dB}$ to $-80 \mathrm{~dB}$ at $100-120 \mathrm{~Hz}$ when the feed-forward loop in used. Nevertheless, real results are not going to be as good as the theoretical ones because it should be taken into account that equation (26) depends on the duty cycle $\mathrm{D}$ and on the input voltage $\mathrm{V}_{\mathrm{g}}$, which have been assumed constant in the analysis (i.e., capital letters represents constant values). However, the duty cycle is not constant as it is going to be changing in order to attenuate the input voltage ripple (i.e., changes in the input voltage). This fact would not represent any problems in a converter in which there were a linear relation between the output voltage and the duty cycle, such as in the Buck converter. Nevertheless, as can be seen from (4), the output voltage depends, among other variables, on the square value of the duty cycle in the AHB. Hence, for high values of $D$, the effectiveness of this solution may be reduced as (26) becomes strongly nonlinear, as can be seen in Fig. 9b. As a consequence, the ripple attenuation that can be achieved with the proposed feed-forward loop is only partial and it may be valid for low or medium-quality applications. Nevertheless, it is possible to enhance the feed-forward effect on the AHB by a modification of the feed-forward loop.

In Fig. 10, a feed-forward loop that distinguishes between increments and decrements of the input voltage is presented. The voltage divider and the band-pass filter remain unchanged. Nevertheless, the output signal of this filter is split in two. The precision rectifier $\mathrm{D}_{\mathrm{i}_{1} 1}$ cancels any negative value of its input signal, keeping only the positive part of the voltage ripple, while the precision rectifier $D_{i_{2} 2}$ cancels any positive value. As a consequence, it is possible to use different feed-forward transfer functions $\left(\mathrm{FF}_{1}(\mathrm{~s})\right.$ and $\left.\mathrm{FF}_{2}(\mathrm{~s})\right)$ for the positive and the negative part of the ripple. The outputs of both transfer functions are added, resulting in an asymmetrical (due to the difference between both transfer functions) control signal optimized for the ripple attenuation. Due to the non-lineal relation between the duty cycle and the output voltage, even with two different transfer functions it is impossible to totally cancel the

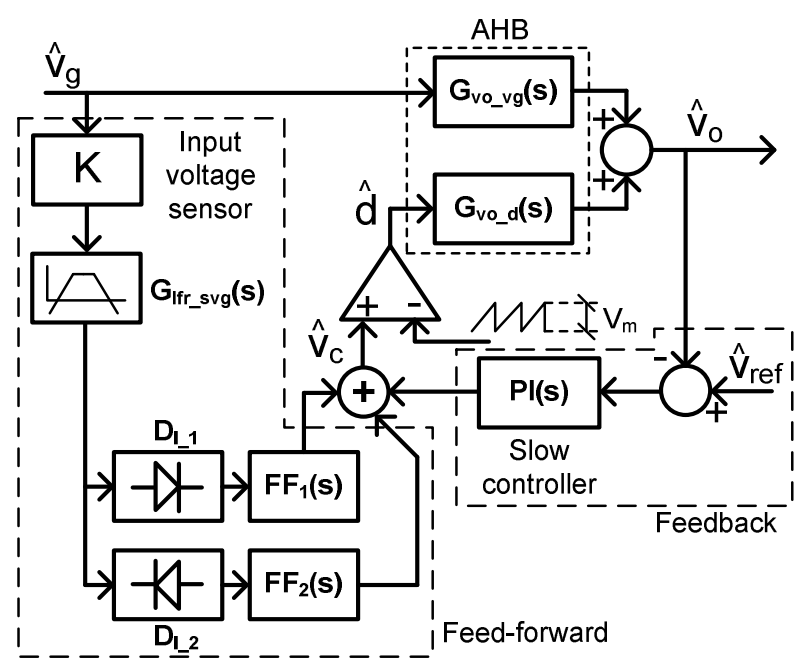

Fig. 10. Block diagram of the proposed feed-forward technique. 
effect of the low-frequency ripple on the output voltage. Nevertheless, it allows us to considerably reduce the ripple in the output voltage and output current of the LED driver.

Calculating $\mathrm{FF}_{1}(\mathrm{~s})$ and $\mathrm{FF}_{2}(\mathrm{~s})$ can still be done by using equation (26), but different values of $\mathrm{D}$ and $\mathrm{V}_{\mathrm{g}}$ have to be chosen for calculating the gain of each transfer function (actually, for calculating $\mathrm{FF}_{\mathrm{p}_{-} 1}$ and $\mathrm{FF}_{\mathrm{p}_{-} 2}$ ). Moreover, it is not obvious to choose these values to optimize the ripple attenuation. Therefore, it is more recommendable to use equation (27), which simplifies the calculation as it depends on the input voltage and the output voltage (which can be considered constant and equal to its maximum value) and not on the duty cycle.

In Fig. 11, the simulation results are given for an AHB without feed-forward, with single feed-forward and with double feed-forward (experimental results will be provided in section V). As can be seen, when the feedforward is not used (Fig. 11a) the closed loop compensator cannot cancel the low-frequency ripple and the output current ripple is as high as $40 \%$. When the simple feed forward is used (Fig. 11b), current ripple decreases to $7 \%$ and, as can be seen, the ac component of the control voltage $\mathrm{V}_{\mathrm{c}}$ has the same amplitude during both halfperiods. When the double feed-forward technique is used (Fig. 11c), the current ripple decreases to $4 \%$ due to the possibility of independently adjusting the gain of each feed-forward compensator $\left(\mathrm{FF}_{\mathrm{p}_{-} 1}\right.$ and $\left.\mathrm{FF}_{\mathrm{p}_{-} 2}\right)$. It should be mentioned that in Fig. 11b, the output current presents a hardly significant $100-\mathrm{Hz}$ component and a significant $200-\mathrm{Hz}$ component. The reason for the $200-\mathrm{Hz}$ ripple is that the static transfer function between the output voltage and the input voltage is nonlinear (see (4)). As a consequence, the perfect cancelation of the $100-\mathrm{Hz}$ ripple would need a nonlinear feed-forward compensator. As the single feed-forward loop used Fig. 11b is linear (its gain is fixed), the cancelation of the ripple is not perfect and a $200-\mathrm{Hz}$ component appears. It should be noted that the amplitude of this $200-\mathrm{Hz}$ ripple is greater than the amplitude of the hardly-significant $100-\mathrm{Hz}$ ripple. This hardly-significant $100-\mathrm{Hz}$ component is the reason why, in Fig. $11 \mathrm{~b}$, the value of the current at $\mathrm{t}=2.5 \mathrm{~ms}$ is slightly
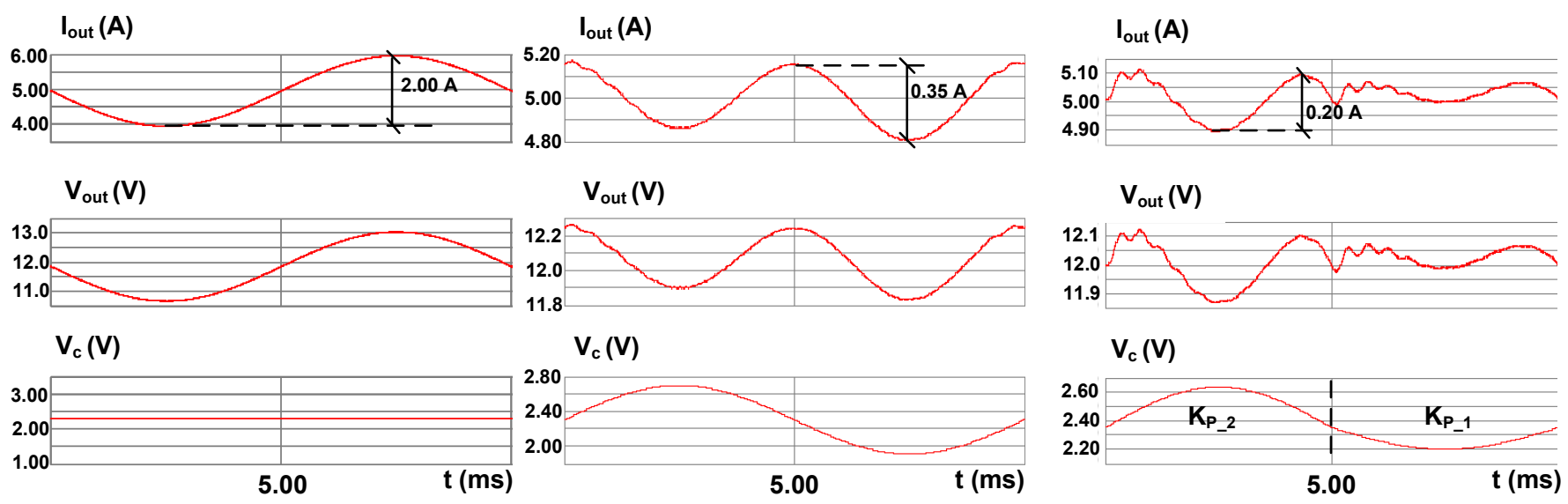

a) higher than the current at $\mathrm{t}=7.5 \mathrm{~ms}$. However, it should be noted that the amplitude of the $200-\mathrm{Hz}$ ripple obtained using the single feed-forward (Fig. 11b) is considerably lower than the amplitude of the $100-\mathrm{Hz}$ ripple obtained when no feed-forward technique is used (Fig. 11a).

Finally, Fig. 11c shows that the achieved ripple attenuation with the double feed-forward technique is better when the input voltage increases $\left(\mathrm{V}_{\mathrm{c}}\right.$ decreases) rather than when the input voltage decreases $\left(V_{c}\right.$ increases). The reason is that equation (4) is more linear when the duty cycle is lower and, as a consequence, the ripple attenuation is better and more precise when the duty cycle decreases.

The key point of the proposed control stage (i.e., designing a slow closed loop controller for adjusting the average value of the output current and a fast feed-forward loop for cancelling the low-frequency ripple) is that it allows the AHB to be used in lighting applications without flickering problems (low-frequency ripple has been reduced from $40 \%$ to $7 \%$ or $4 \%$ ) while keeping the advantages of its high efficiency and small output filter (i.e., it can be implemented without electrolytic capacitor). Another important point is that the difference between the ripple with the single feed-forward loop and the ripple with the double feed-forward loop is $3 \%$. First, this $3 \%$ represents reducing the ripple nearly to the half (from $7 \%$ to $4 \%$ ). Second, this reduction is achieved at virtually nocost: the difference in the control stage is the additional compensator $\mathrm{FF}_{2}(\mathrm{~s})$, which represents just one more lowcost operational amplifier. Therefore, although both feedforward techniques offer satisfactory results, for highquality applications in which the flickering has to be strongly reduced, the double feed-forward technique represents the best option at the same cost.

\footnotetext{
Fig. 11. Simulation results for an AHB with a) no feed-forward loop; b) single feed-forward loop; c) double feed-forward loop. For these simulations: $\mathrm{V}_{\mathrm{g} \_ \text {nom }}=425 \mathrm{~V}, \mathrm{~V}_{\mathrm{g} \_ \text {max }}=470 \mathrm{~V}, \mathrm{~V}_{\mathrm{g} \_ \text {min }}=380 \mathrm{~V}, \mathrm{n}_{1}=0.084, \mathrm{n}_{2}=0.04, \mathrm{~V}_{\text {out }}=12 \mathrm{~V}, \mathrm{I}_{\text {out }}=5 \mathrm{~A}, \mathrm{~K}=0.0033$.
} 


\section{EXPERIMENTAL RESULTS}

A $60-\mathrm{W}$ prototype (see Fig. 12) has been built in order to verify the proposed feed-forward technique and the proposed SD-SR driving circuits. The output voltage is $12 \mathrm{~V}$ and the nominal current is $5 \mathrm{~A}$ (standard requirement in LED lighting applications). The input voltage of the AHB is provided by a Boost converter with a nominal output voltage of $425 \mathrm{~V}$ and a low-frequency ripple of $15 \%$. The output capacitor of this Boost converter is implemented with Metallized Polypropylene (MKP) film capacitors from EPCOS high density series. The transformer is built with an ETD34 while the output inductor is built with a vertical E30. The MOSFETs in the primary side are STD12N65 and the MOSFETs in the secondary side (two in parallel) are NTD5867. The Schottky diodes in parallel with the secondary MOSFETs are MBRD660CT. The load used for carrying out the tests consists of 15 LED strings in parallel with 3 LEDs per string. These LEDs are W4218T2-SW from Seoul Semiconductors (distributed by Avnet). They belong to the Z-Power LED family. Their nominal forward current is $0.350 \mathrm{~A}$ and their nominal forward voltage is $3.25 \mathrm{~V}$ (the nominal power of each LED is $1.14 \mathrm{~W}$ ).

In Fig. 13, the ZVS achievement in primary switches is shown. In this particular case, the energy stored in the leakage inductance was not enough and it was increased by adding some gap to the transformer core as explained in [14].

In Fig. 14a, the output current and the output voltage are shown when the input voltage is affected by a $100-\mathrm{Hz}$ peak-to-peak ripple of $15 \%$ (also shown in Fig.

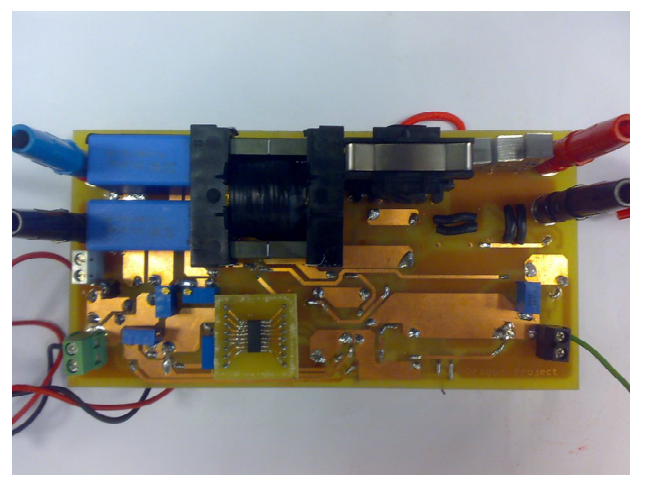

Fig. 12. Photograph of the prototype. 14a) and the proposed feed-forward technique is not used. As it has been explained in section IV, the designed feedback loop cannot cancel the output voltage ripple due to the low switching frequency chosen in order to maintain low switching losses. Moreover, the peak-to-peak outputcurrent ripple is even higher, reaching $35 \%$, due to the low value of the dynamic resistance of the LEDs. In Fig. 14b, the results obtained with the single feed-forward loop proposed in Fig. 8 are presented. As can be seen, the output voltage and output current low-frequency ripples are considerably reduced (output current ripple is around $10 \%$ ). Nevertheless, the optimization cannot be achieved for all input voltages. In Fig. 14c, the results with the double feed-forward loop are shown. As can be seen, output ripple is reduced due to the possibility of optimizing two different gains in the feed-forward loop. The resulting low-frequency ripple is as low as $4 \%$ and it has been obtained with a converter without electrolytic capacitor. Therefore, it is perfectly valid for any highquality application which demands high reliability and low output current ripple.

Regarding SD-SR, Fig. 15a shows the voltage in the secondary side of the transformer $\left(\mathrm{V}_{\text {tr_2 } 2}\right)$ for the nominal input voltage. As can be seen, when $\mathrm{V}_{\mathrm{tr}_{-} 2}$ is positive, its value is considerably higher than the maximum $\mathrm{V}_{\mathrm{GS}}$ voltage withstood by the MOSFET gate. Therefore, it cannot be directly used as driving signal. When it is negative, the value is valid as driving signal. Nevertheless, this is not true for any input voltage, as can be seen in Fig. 3. Nevertheless, the driving signals can be adapted to be inside the minimum and maximum limits for a proper operation of the SR MOSFETs (see Fig. 15b)

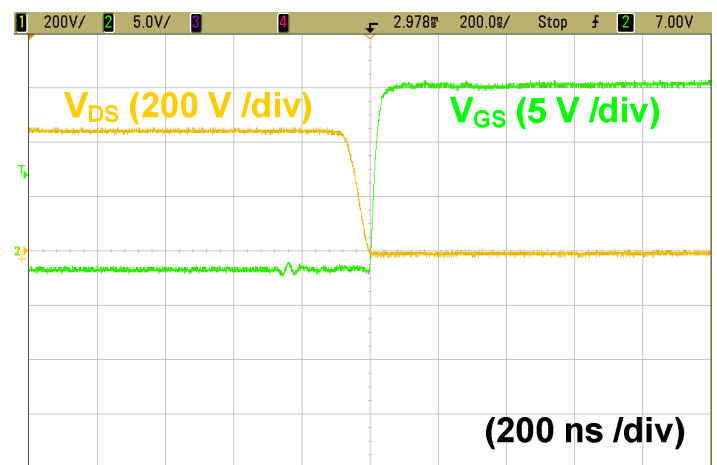

Fig. 13. ZVS achievement in primary switches

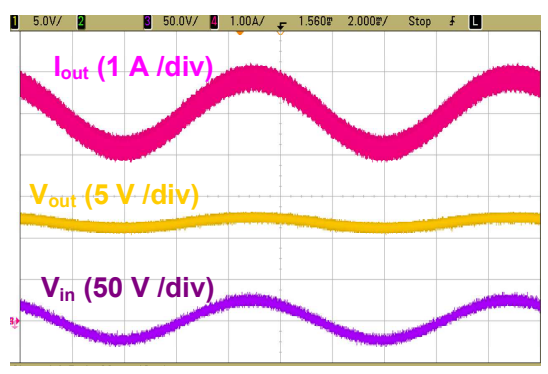

a)

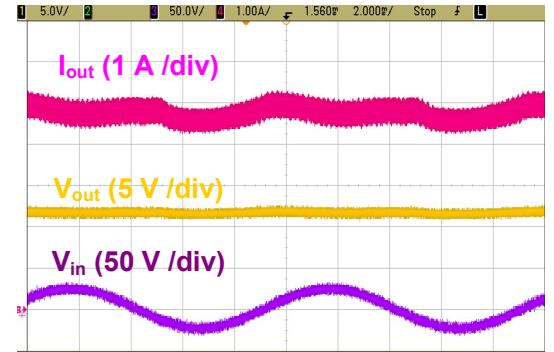

b)

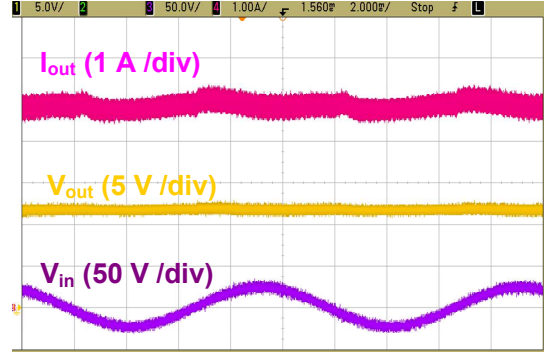

c)

Fig. 14. Output current, output voltage and input voltage ripple when: a) the feed-forward technique is not implemented; b) the single feed-forward technique is implemented; c) the double feed-forward technique is implemented. 


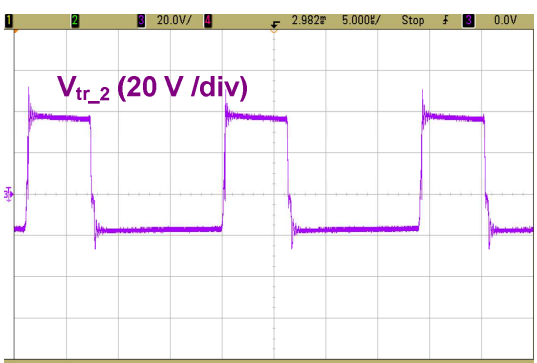

a)

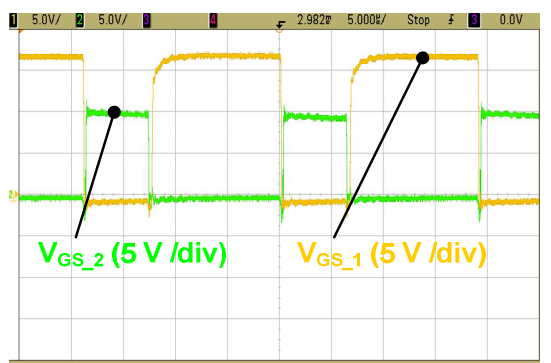

b)

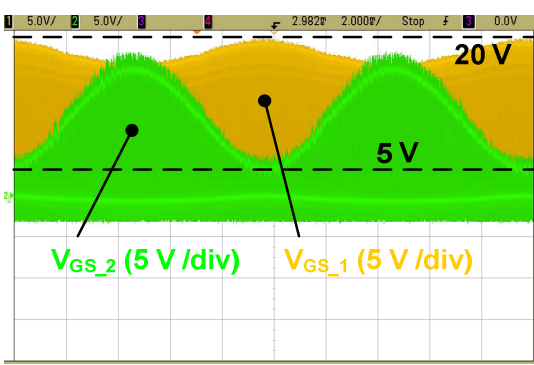

c)

Fig. 15. a) Voltage of the secondary side of the transformer; b) $V_{G S}$ of both SR MOSFETs; c) $V_{G S}$ of both SR MOSFETs when the input voltage is affected by a $20 \%$ peak-to-peak relative ripple.

when the driving circuits proposed in Fig. 10 are used. Besides, the two driving signals when the input voltage is affected by the low-frequency ripple are shown in Fig. $15 \mathrm{c}$. As can be seen, none of the limits (20 V for the upper limit and around 6-7 V for the lower one) is exceeded thanks to the driving circuit design. It should be mentioned that high-value resistors have been connected in parallel to the capacitors used in the driving circuits of SR MOSFETs in order to allow them to adapt its voltage to the voltage variations caused by the low-frequency ripple.

The efficiency for different dc input voltages is shown in Fig. 16a. It should be taken into account that, apart from reliability, the other main concern is efficiency. As can be seen, it reaches a maximum peak of $94.5 \%$. Considering that the Boost converter operating in BCM reaches an efficiency as high as $97-98 \%$, the overall efficiency of the whole topology (two-stage topology) is as high as 91.6-92.6\%, which is an outstanding result for a 12-V LED driver without electrolytic capacitors. In Fig. $16 \mathrm{~b}$, the efficiency when the input voltage is affected by different peak-to-peak $100-\mathrm{Hz}$ relative ripples is shown.

Finally, it may be interesting to analyse which is the most suitable switching frequency for this topology. In Fig. 16c, the efficiency for different switching frequencies is shown. The magnetic components (transformer and inductor) are designed choosing the most suitable core material, number of turns, etc. in order to optimize the magnetic-component design for the chosen switching frequency but keeping the same size (ETD34 for the transformer and E30 for the inductor). In this way, efficiency results can be directly compared. As can be seen, efficiency increases as switching frequency decreases. Considering that size is mainly determined by the first-stage output capacitor, the switching frequency reduction in the second stage does not significantly affect the overall size while it increases the efficiency.

\section{CONCLUSIONS}

Two-stage LED drivers are normally used when the topology cannot be implemented with electrolytic capacitors. In this case, the first stage is in charge of performing the power factor correction, providing an output voltage with large low-frequency ripple because of the use of non-electrolytic capacitors while observing size constraints. This low-frequency ripple must be attenuated by the second stage. The AHB is a topology with outstanding characteristics for being used as this second stage. Its output filter is smaller than in other topologies so that it can be easily implemented without electrolytic capacitors either. Besides, it provides galvanic isolation (sometimes a customer requirement, especially in lowoutput-voltage applications) with very high efficiency. Nevertheless, its controller cannot be as fast as needed in order to cancel the low-frequency ripple in its input voltage due to stability reasons. Taking into account that the LEDs are slow loads, it is possible to design a feedforward loop optimized for cancelling this low-frequency ripple while the closed loop control assures stability and

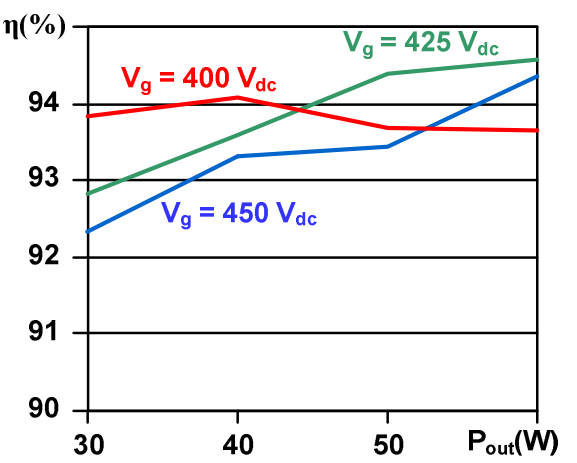

a)

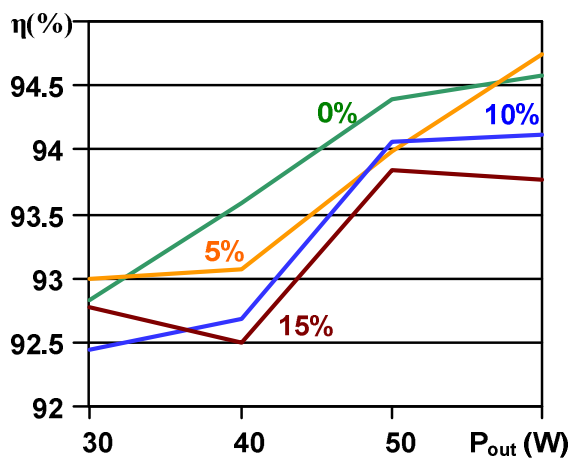

b)

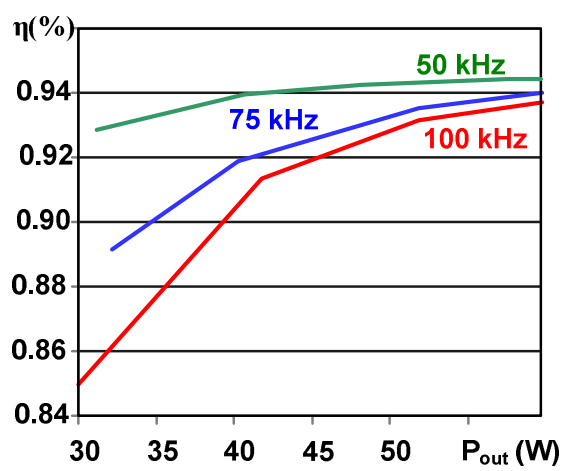

c)

Fig. 16. Efficiency for a) different input voltages; b) different peak-to-peak relative ripples $\left(\mathrm{V}_{\mathrm{g}}=425 \mathrm{~V}\right)$; $\left.\mathrm{c}\right)$ different switching frequencies. Note: a) and b) are obtained for a switching frequency of $50 \mathrm{kHz}$. 
output voltage regulation due to variations in the characteristics of the LEDs, which are determined by their warming-up.

For low-output-voltage applications, SR is mandatory in order to obtain high efficiency. In this paper, a SD-SR technique specially designed for the AHB is proposed. This specific design takes into account that the voltage in the secondary side of the transformer of the AHB changes, not only with input voltage variations, but also with the output voltage variations due to dimming.

Experimental results with a $60-\mathrm{W}$ prototype with an output voltage of $12 \mathrm{~V}$ validate the proposed feed-forward technique and the proposed SD-SR circuit. No electrolytic capacitor is needed and the efficiency in the AHB is as high as $94.5 \%$. Taking into account that the first stage is a Boost converter with efficiency as high $97 \%$ (and without electrolytic capacitor), the overall efficiency of the proposed topology is $91.6 \%$, considerably higher than in other electrolytic-capacitor-free topologies with the same output voltage.

\section{ACKNOWLEDGEMENTS}

This work has been supported by Spanish Government under projects RUE-10-CSD2009-00046 FEDER Funds and MICINN10-DPI2010-21110-C02-01 and by company AEG Power Solutions B.V. under project FUO-EM-002-10.

\section{REFERENCES}

[1] T. Siew-Chong, "Level Driving Approach for Improving Electrical-to-Optical Energy-Conversion Efficiency of Fast-Response Saturable Lighting Devices," Industrial Electronics, IEEE Transactions on, vol. 57, pp. 1342-1353, 2010.

[2] B. Lehman and A. Shteynberg, "Professional Education Seminars: LED lighting: trends, standards, optics and power electronics," presented at Applied Power Electronics Conference and Exposition (APEC), Fort Worth, 2011.

[3] K. I. Hwu, Y. T. Yau, and L. Li-Ling, "Powering LED Using High-Efficiency SR Flyback Converter," Industry Applications, IEEE Transactions on, vol. 47, pp. 376-386, 2011.

[4] M. Arias, A. Vázquez, and J. Sebastián, "An Overview of the AC-DC and DC-DC Converters for LED Lighting Applications," Automatika - Journal for Control, Measurement, Electronics, Computing and Communication, vol. 53, p. 17, 20122012.

[5] D. G. Lamar, J. Sebastián, A. Rodríguez, M. Rodríguez, and M. M. Hernando, "A Very Simple Control Strategy for Power Factor Correctors Driving High-Brightness LEDs," Power Electronics, IEEE Transactions on, vol. 24, pp. 2032-2042, 2009.

[6] Y. Hu, L. Huber, and M. Jovanovic, "Single-Stage, Universal-Input AC/DC LED Driver with Current-Controlled Variable PFC Boost Inductor," Power Electronics, IEEE Transactions on, vol. PP, pp. 1-1, 2010.

[7] D. Gacio, J. M. Alonso, A. J. Calleja, J. Garcia, and M. RicoSecades, "A Universal-Input Single-Stage High-Power-Factor Power Supply for HB-LEDs Based on Integrated Buck-Flyback Converter," Industrial Electronics, IEEE Transactions on, vol. 58, pp. 589-599, 2011.

[8] L. Wai-Keung, K. H. Loo, T. Siew-Chong, Y. M. Lai, and C. K. Tse, "Bilevel Current Driving Technique for LEDs," Power Electronics, IEEE Transactions on, vol. 24, pp. 2920-2932, 2009.

[9] Q. Hu and R. Zane, "Minimizing Required Energy Storage in Off-line LED Drivers Based on Series-input Converter Modules," Power Electronics, IEEE Transactions on, vol. PP, pp. 1-1, 2010.
[10] Y. Wensong, L. Jih-Sheng, M. Hongbo, and Z. Cong, "High-Efficiency DC-DC Converter With Twin Bus for Dimmable LED Lighting," Power Electronics, IEEE Transactions on, vol. 26, pp. 20952100, 2011.

[11] ST, "AN2983 Application Note," 2010.

[12] D. Bailey, "An Idea to Simplify LED Lighting Purchase Decisions," Bodo's Power, pp. 18, 2011.

[13] X. Qu, S. C. Wong, and C. K. Tse, "Resonance-Assisted Buck Converter for Offline Driving of Power LED Replacement Lamps," Power Electronics, IEEE Transactions on, vol. 26, pp. 532-540, 2011.

[14] M. Arias, D. Lamar, F. Linera, D. Balocco, A. Diallo, and J. Sebastian, "Design of a Soft-Switching Asymmetrical Half-Bridge Converter as second stage of a LED driver for Street-Lighting Application," Power Electronics, IEEE Transactions on, vol. 27, pp. 1608-1621, 2012.

[15] J. Sebastian, J. A. Cobos, O. Garcia, and J. Uceda, "An overall study of the half-bridge complementary-control DC-to-DC converter," presented at Power Electronics Specialists Conference, 1995. PESC '95 Record., 26th Annual IEEE, 1995.

[16] R. Oruganti, H. Phua Chee, J. T. K. Guan, and C. Liew Ah, "Soft-switched DC/DC converter with PWM control," Power Electronics, IEEE Transactions on, vol. 13, pp. 102-114, 1998.

[17] W. Eberle, H. Yongtao, L. Yan-Fei, and Y. Sheng, "An overall study of the asymmetrical half-bridge with unbalanced transformer turns under current mode control," presented at Applied Power Electronics Conference and Exposition, 2004. APEC '04. Nineteenth Annual IEEE, 2004.

[18] R. Miftakhutdinov, A. Nemchinov, V. Meleshin, and S. Fraidlin, "Modified asymmetrical ZVS half-bridge DC-DC converter," presented at Applied Power Electronics Conference and Exposition, 1999. APEC '99. Fourteenth Annual, 1999.

[19] O. Garcia, J. A. Cobos, J. Uceda, and J. Sebastian, "Zero voltage switching in the PWM half bridge topology with complementary control and synchronous rectification," presented at Power Electronics Specialists Conference, 1995. PESC '95 Record., 26th Annual IEEE, 1995.

[20] C. Huang-Jen, L. Yu-Kang, C. Jun-Ting, C. Shih-Jen, L. Chung-Yi, and M. Shann-Chyi, "A High-Efficiency Dimmable LED Driver for Low-Power Lighting Applications," Industrial Electronics, IEEE Transactions on, vol. 57, pp. 735-743, 2010.

[21] J. Wang, J. Zhang, X. Wu, Y. Shi, and Z. Qian, "A novel high efficiency and low-cost current balancing method for multi-LED driver," presented at Energy Conversion Congress and Exposition (ECCE), 2011 IEEE, 2011

[22] Q. Xiaohui, W. Siu-Chung, and C. K. Tse, "Noncascading Structure for Electronic Ballast Design for Multiple LED Lamps With Independent Brightness Control," Power Electronics, IEEE Transactions on, vol. 25, pp. 331-340, 2010.

[23] H. Ma, W. Yu, C. Zheng, J.-S. Lai, Q. Feng, and B.-Y. Chen, "A universal-input high-power-factor PFC pre-regulator without electrolytic capacitor for PWM dimming LED lighting application," presented at Energy Conversion Congress and Exposition (ECCE), 2011 IEEE, 2011

[24] H. Ma, W. Yu, Q. Feng, J.-S. Lai, and C. Zheng, "A novel SEPIC-derived PFC pre-regulator without electrolytic capacitor for PWM dimming LED lighting application based on valley fill circuit," presented at Energy Conversion Congress and Exposition (ECCE), 2011 IEEE, 2011.

[25] G. Linlin, R. Xinbo, X. Ming, and Y. Kai, "Means of Eliminating Electrolytic Capacitor in AC/DC Power Supplies for LED Lightings," Power Electronics, IEEE Transactions on, vol. 24, pp. 1399$1408,2009$.

[26] W. Beibei, R. Xinbo, Y. Kai, and X. Ming, "A Method of Reducing the Peak-to-Average Ratio of LED Current for Electrolytic Capacitor-Less AC-DC Drivers," Power Electronics, IEEE Transactions on, vol. 25 , pp. 592-601, 2010.

[27] B. Lehman, A. Wilkins, S. Berman, M. Poplawski, and N. Johnson Miller, "Proposing measures of flicker in the low frequencies for 
lighting applications," presented at Energy Conversion Congress and Exposition (ECCE), 2011 IEEE, 2011.

[28] A. Wilkins, J. Veitch, and B. Lehman, "LED lighting flicker and potential health concerns: IEEE standard PAR1789 update," presented at Energy Conversion Congress and Exposition (ECCE), 2010 IEEE, 2010 